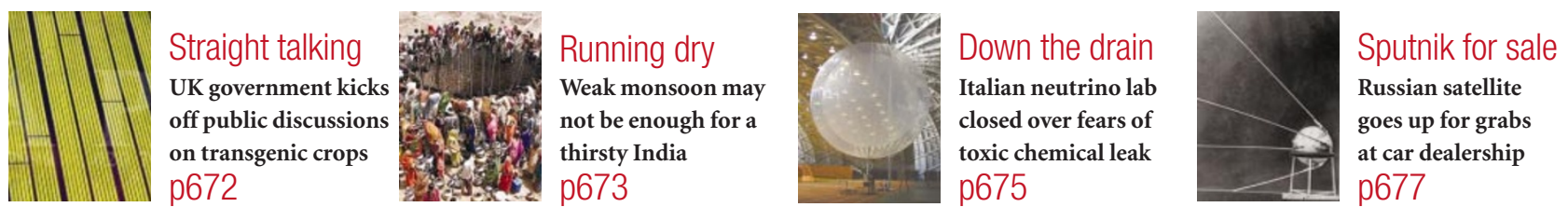

\title{
Astronomers leap to defence of extra seconds in time debate
}

\section{Geoff Brumfiel, Washington}

What time is it? For air-traffic controllers, astronomers, computer network managers and others in search of the real answer to this everyday question, a battle royal is set to erupt.

Experts are trying to agree on whether the long-standing practice of inserting occasional 'leap seconds' into coordinated universal time - the standard time reference used by clocks around the world - should be abandoned. The body that will decide how to resolve the issue, the International Telecommunication Union (ITU), is now asking astronomers for their input.

Since the practice began in 1972, 32 leap seconds have been added to universal time, mainly to keep it in synch with the rotation of the Earth as it slows down under the gentle drag of the Moon's gravitational field.

Astronomers want to continue adding leap seconds because keeping universal time in line with the Earth's rotation means that telescopes can find stars and galaxies in their rightful places in the sky. But no one navigates by the stars any more, and adding leap seconds creates extra work all round.

Most of those involved want to quit the practice, and get universal time back in alignment with the other main reference for timekeepers - atomic time, as assiduously maintained by the Bureau International des Poids et Mesures in Paris. If the change is implemented, "the old meaning of time will become ambiguous," warns Steve Allen, an astronomer at the Lick Observatory in Santa Cruz, California.

But William Klepczynski of Global Timing Services, which consults for the US Federal Aviation Administration, fears that keeping leap seconds will lead to trouble, perhaps even big trouble - such as a plane crash. "There have been no accidents yet, but I think the potential is there," he contends.

Confusion caused by the divergence of universal time and atomic time has been further exacerbated by the architects of the Global Positioning System (GPS). The GPS began on universal time in 1980 but wasn't adjusted by adding any of the 13 leap seconds since then because its carefully synchronized

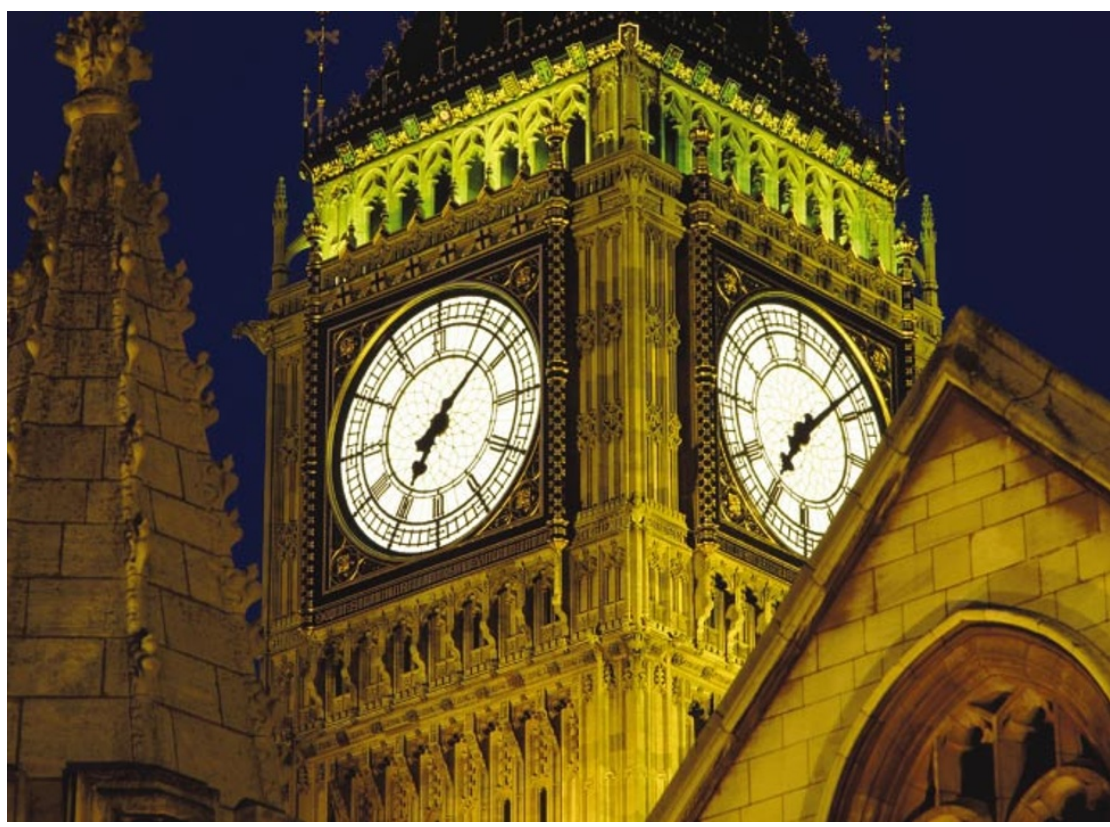

Time for a change? The issue of leap seconds has split researchers who need an accurate time standard.

satellite network can't cope with them.

As a result, Klepczynski says, gaps of several seconds' duration are opening up between the world's navigation systems and the universal time used by pilots and airtraffic controllers. These can confuse sensitive aircraft navigation systems, and the only way to avoid disaster, he says, is to detach universal time from the Earth's rotation and make it the standard for all navigation.

But separating time from rotation would mean that telescopes would no longer function properly, according to Patrick Wallace, an astronomer at the Rutherford Appleton Laboratory in Oxford, UK. Most telescopes with a viewfinder wouldn't be immediately affected, but instruments that track satellites and other moving objects could feel the effects within a few years, Wallace warns.

Allen says that it could cost between US $\$ 10,000$ and US $\$ 100,000$ for each telescope to correct the problem, and that corrections will be tricky to implement.

Then there is the problem that, without the leap seconds, day will turn into night.
"In principle, you could eventually find that you're having lunch when it's getting dark," Wallace says.

Compromise solutions don't seem to please anyone. Wallace says that an idea to change the length of the second is "completely lunatic". A more prosaic plan to replace the leap second with a leap hour, to be inserted in a few centuries' time, is condemned by Klepczynski as "inelegant".

The decision about whether to drop the leap second is being studied by a working group on time signals set up by the ITU's Radiocommunication sector. The group's chairman, Ronald Beard of the Naval Research Laboratory in Washington DC, says he needs more input from people who use universal time. "Many people don't even know that leap seconds exist," he complains.

Beard's working group hopes to come up with a plan in time for the ITU's next World Radiocommunication Conference, probably in 2006 (see page 675). But it could take years for the ITU to finally agree what time it is, he predicts. 